\title{
Challenges for Professional Development of Malaysian ESL Teachers
}

\author{
Ruzana Omar ${ }^{1}$, Radzuwan Ab. Rashid $^{2}$, and Azweed Mohamad ${ }^{2}$ \\ ${ }^{1}$ Universiti Technology MARA, Malaysia \\ ${ }^{2}$ Universiti Sultan Zainal Abidin, Trengganu Malaysia
}

\section{Abstract}

The paper aims to provide insights into the current understanding of the challenges faced by in-serviced primary school ESL teachers in completing their degree on a part-time basis. In relation to the government's effort to improve the quality of primary education, many English language teachers have enrolled in the 'Teacher's First-degree program' offered by the Ministry of Education. The participants of the program, somehow, face a number of challenges. As adult learners, the ESL teachers need to follow in doing the degree part time as all of them are full time teachers and teaching in different schools. Sociocultural theory of Lev Vygotsky provided

Corresponding Author:

Ruzana Omar

ruzana@tganu.uitm.edu.my

Received: 1 July 2019

Accepted: 18 July 2019

Published: 31 July 2019

Publishing services provided by Knowledge

(c) Ruzana Omar et al. This article is distributed under the terms of the Creative Commons

Attribution License, which permits unrestricted use and redistribution provided that the original author and source are credited.

Selection and Peer-review unde the responsibility of the AICLL 2019 Conference Committee. the theoretical framework for this case study. This qualitative study explored the experiences of five in-service primary school English language teachers who were involved in the program. Semi-structured interviews were carried out to identify the challenges faced by the teachers in completing a primary school teacher's first-degree program organized by the Ministry of Education (MOE). The main data generated from semi-structured interviews was analysed using thematic analysis approach. The findings revealed that job commitments, family commitments, health mental issue and time management are the main challenges faced by them. Exploring in-service primary school English teachers challenges in furthering their studies part-timely might give the Ministry of Education (MOE) consideration in understanding of language teachers' selves and needs while pursuing their first degree. This research might also be helpful to investigate the current practices of the professional development of primary school English teachers in Malaysia.

Keywords: ESL teacher, teacher professional development, part-time degree, inservice teacher, challenges

\section{Introduction}

In relation to the issue of the government effort to be having a graduated in-service Primary school teachers, many of the teachers had registered themselves to the program with intending to develop themselves professionally. The participants of the program, somehow, face a number of challenges in providing professional development for educators of adult learning English as a second language (ESL). The main problem of the program is, adult ESL teachers need to follow in doing the degree part time as 
all of them are full time teachers and teaching in different schools located at different districts throughout the state (Mathews-Aydinli \& Taylor, 2005). Facilities for providing professional development may be located far from one another within a state.

Following that, poor attendance of students and a few failures cases had also been reported due to teachers' problems to manage their time between their job at school and their commitment as a student. Choy (2002) indicates that part-time student meets their objective of bachelor-degree completion at a rate of 16.9 percent, compared to 53.9 percent of traditional students with the same goal. The probable factors are due to teachers who were required to follow the program in the midst of their heavy responsibility at school. It would not be very wise to be having it while being in service. For they might not be able to give their full attention to their teaching and play their role as a responsible teacher in school.

Hence, it would be interesting to develop an understanding of the challenges faced by the primary school English in completing their degree on part time basis and the solutions that would have been taken by them.

This study intends to provide a contribution that expands the discussion on the obstacles and barriers of Part-time Primary school English Language teachers in the pursuit of completing their degree while developing themselves professionally in the field of education.

The objectives of this research intend to develop an understanding of:

- The challenges faced by the primary school English teachers in completing their degree part-timely.

\section{Literature Review}

\subsection{Teachers' professional development}

Darling-Hammond and McLaughlin (1995) state that teacher development needs to focus on deepening teachers' understanding of the process of teaching and learning and of the students they teach because effective professional development involves teachers both as learners and teachers. This suggests that Primary school ESL teachers should be made responsible for developing themselves professionally in order to gain confidence in teaching and deepening their knowledge albeit the challenges they have to go through if they have to do it on part-time basis. It is more often than not, they would become more confident after deepening their knowledge of teaching where the students would understand them better and enjoy their teaching. Thus, it is hopeful that 
by doing so, they would also be gaining respects from their colleagues, society as well as their students.

Professional development is also regarded as an individual achievement or personal affair of one person. An English teacher for instance would seek for new knowledge professionally based on their own needs. Thus, one teacher needs dissimilar to another according to their priority. Nias (1996) as cited by Ali (2000) states that "ESL teachers in their quest for personal development, and indirectly organization development, acted more or less as isolated individual. As they saw their own teaching a private affair, often they identified their own needs and skills; they prioritized them and discovered ways to meet their own development" (p. 47). As in-serviced teachers who are teaching in a primary school, they must have their own dreams to climb up a higher ladder of grades or to seek opportunity of higher incomes, based on their own personal needs with the degree that they had worked for. Hence, by developing themselves professionally would be an impetus for them to move further in their career ladder rather than being stagnant in school.

In the following sections is a more detailed examination of how professional development is related to English Language teachers.

\subsection{Challenges to improve the status of teachers through profes- sional development}

There is a national concern to improve the level of education in Malaysia and this has led the Ministry of Education to restructure the national curriculum. In 2010, the Ministry introduced the Malaysian Curriculum Standard Document (KSSR) and implemented the system in Primary schools throughout the country. Following that, the Malaysian Education Blueprint (2013-2025) introduced eleven shifts in 2013 to transform the education system (Ministry of Education Malaysia, 2013).

In line with this transition, one of the shifts aimed to increase the quality of CPD for teachers. This has led to a restructuring of the type of courses and the delivery mode for CPD on a national level. In 2014, the Ministry of Education (Teacher Education Division, 2014) introduced the CPD Masterplan (Pelan Induk Pembangunan Professionalisme Keguruan) which aimed to be implemented concurrent with the shifts outlined in the Malaysia Education Blueprint.

The government has also taken great measures in achieving its graduate target in primary and secondary education, strategizing teacher development program, fulfilling the aspirations of education defined by National Key Results Areas (NKRA) and definitely 
improving to the great extend proficiency and mastery in the English language. One of the strategies to improve the status of in-service primary school teachers is by increasing the number of qualified graduated teachers via professional development in a program which is called 'Teachers' First- Degree Program'. Somehow, the implementation of the program has become a great challenge to the teachers in terms of allocation of their time, among others, towards the program. Hence, this study will explore the teachers' experiences in pursuing their professional development with the intention to give useful insights to other in-service teachers who are to go through the same journey in the future.

\subsection{Towards achieving the target of qualified graduate teachers (Teachers' first-degree program) and its challenges}

The government has furthered its commitment of achieving a $25 \%$ target of teachers in primary school and $100 \%$ of secondary school teachers with degree qualification. Since the beginning of $2004 \mathrm{MOE}$ embarked in a program to upgrade the quality of its primary education, with the hope to develop its teachers professionally. Due to that reason, teachers were encouraged to upgrade their teaching qualifications through distant education and in-service training in local or foreign universities, which was under the MOE's continuous professional development program. Despite having achieved an increase to $13.7 \%$ for primary school and $87.1 \%$ for secondary school by 2008 , the government faces the challenges to produce quality teachers who are able to discharge curriculum delivery challenges efficiently. Further, it faces the challenge to administer frequent monitoring through administer supervision by the government agencies (Jamil, Abd Razak, Raju, \& Mohamed, 2010).

In achieving the target of qualified graduate teachers by MOE, there are many obstacles though being faced by Primary school English Language teachers that seek the attention by the Ministry in order to reduce the number of non-graduates among them. Silva, Calahan, and Lacireno-Paquet (1998) concurred that lack of time, family commitments, location and cost of classes are the four specific factors that can serve as challenges to further education for adult learners. They agreed with the idea that these constraints can directly and indirectly impact the time to receive a degree and the ability for a student to persist, which especially affected the adult learners who hold their full- time employment while furthering their studies (Kazis et al., 2007). 


\subsection{The part and parcel of part time learning}

Part-time studies are often categorized under discussion of education fraternities compared to full time students. An exception to this is the review of barriers to widening participation by Gorard et al. (2006). Thus, it would be interesting to explore and be given more attention to the obstacles that have been faced by the in-service Primary school English teachers who had taken up the Degree program on part-time basis, that is yet to be tapped by previous researchers. Currently, in order to get more teachers to be involved in the Graduating Primary school teachers' program and at the same time in dealing with the problem of in-service teachers not to leave their job while pursuing their first degree, the Ministry of education has opted for a part-time mode of learning for this group of teachers as a solution.

Although some of the previous studies deal explicitly with part time students, the nature of part-time of their studies may not be the central focus of attention, but other factors, notably students' characteristics as mature students may be at the heart of the study (Jones \& Rothbart, 2003). Nonetheless, as reflected in the topic of this research, the central focus of attention would be given to the very crux of the experiences that the in-service teachers went through in dealing explicitly with their everyday life as a part time student-teacher.

\section{Research Method}

A qualitative approach had been employed to collect the data. There are reasons to justify the usage of the approach. Firstly, based on qualitative approach, data had been collected via interview to investigate the challenges that the in service-primary school teachers had gone through while pursuing their studies in doing a first degree on part time basis.

\subsection{Selection of participants}

Five in-service ESL teachers who had involved themselves in professional development by pursuing their first degree on part time basis had been chosen. The main reason for selecting participants with this profile is that they would provide richer accounts of the impact that these professional life experiences have on their teacher selves. The participants in this study had been graduated from following a degree course at a local university on part time basis. The different background and varied experiences of the 
participants had contributed to rich data generation. The first participant, Maria (P1), is a hard-working female teacher, holding many posts in her school and has been teaching at various primary schools in the districts of her states for more than 15 years. The second participant, Yazid (P2), is a male senior teacher with more than 25 years of teaching experience, residing and teaching in an urban school and holding the post of a senior assistant in his school. The third participant, Aziah (P3), a female teacher, has more than 10 years teaching experience and teaching at a sub rural school. She has an expertise of teaching a lower primary school level in her school for being entrusted teaching Year 1 for many years. The fourth participant is Shazlin (P4), teaching in a rural school with more than 10 years of teaching English language at various primary schools in the northern state before residing and teaching in her current school in the east of Peninsular Malaysia. The fifth participant, Farizah (P5), has been teaching English language in a sub-urban primary school for more than 15 years and has been entrusted to teaching Year 6 , the class with the pupils who are sitting for public examination in her school.

\subsection{Procedure}

Semi-structured Interviews had been conducted to generate the data on teachers' experience in facing the barriers while doing their first degree at a university and at the same time having a teaching job at a primary school. Interviews are generally used in social research to elicit deep-rooted beliefs and feelings from the participants which other methods, such as observations, analysis of documents, or questionnaires are not able to elicit (Wragg, 2002).

\subsection{Data analysis}

The data were collected from all the five participants. The data were then transcribed after this process of the initial thoughts and ideas were noted down where it is considered as an important stage in analysis (Riessman, 1993). The coding phase took place after the initial stage and building on the notes and ideas generated through transcription and data immersion. The codes would then be identified based on features of the data where it is vital to the research question. The third stage involved themes identification; by combining the codes within the data that may have been considered having the same aspect or may have been very similar. A theme would then be produced based on the cooperation of all initial codes that are relevant to the research question. 
The final phase of analysis involves defining and naming the themes, accompanied by a detailed analysis

\section{Result and Discussion}

Based on the semi-structured interview that had been carried out on the five participants, there are four main themes that had been emerged; namely family commitments, job responsibilities, time management and health and mental well-being.When asked on which is the greatest challenge while pursuing their First-degree on a part-time basis all of the participants concurred on the issue that job commitments had been the most challenging in their life, followed with family commitments, time management and least of all health issue.

\subsection{Job commitments}

Job commitment had been placed as the greatest challenge by (P4, OEI) while following this program. It must be arduous for the participant to be allocated additional responsibilities in school apart from attending to learning attachment. The extra tasks had resulted the feeling of resentful, as described in extract 1.

\section{Extract 1}

I felt like I didn't have enough rest, as I was teaching Year six (the group of students who are sitting for a public examination, namely UPSR). I need to tolerate with the extra work and responsibility of tasks given to me by the school's administration in preparing them for the public examination.

(OEI/P5)

That was concurred by (P5, OEI). The description is implied in her chaotic lifestyle in order to carry out the responsibilities in school and to complete the student-teacher's learning task simultaneously. It was pretty much exhausted, as being described in extract 2. 


\section{Extract 2}

The kind of life I lead during my stint as a student-teacher was very challenging and hectic, juggling from work place and campus. It was added with tons of work at school and assignments in college. It was pretty much exhausted.

(OEI/P5)

Both the findings above are concurred with previous studies done by Badri, Al Nuaimi, Guang, and Al Rashedi (2017) on the needs, impacts and barrier of teacher professional development where they found that the most significant barrier to participating in professional development is related to conflict with work schedule.

\subsection{Family responsibilities}

The participants of this study are obliged to family commitment as adult learners. The challenge for (P1, OEI) was tremendous for the attention spent on studies as much needed as caring for her small infant. She has a great challenge in playing her role concurrently as a parent, a student and a school teacher. That represents in extract 3.

\section{Extract 3}

My memory went back at the time I was reading the notes for a test while trying to put my baby to sleep in her cot (chuckling). The feeling of sadness crept in at times.

\section{(PI/FC/OEI)}

Triangulating a few chores is a part of being a student-teacher. Responsibility of filial piety is shown by (P2, OEI) in between school and studying part-timely. Extract 4 shows his expression.

\section{Extract 4}

At that moment, not only I had to juggle my time between my studies and responsibilities at school, but also, looking after my sick father at the hospital. That was tough.

\section{(P2/FC/OEI)}

Triangulating being male head of household, patriarchy obligation, a student and a school teacher proves to be tough for him. 
Despite the responsibilities towards her family, (P4, OEI) didn't lose focus on her priority on school teaching in the midst of being a student herself. Extract 5 shows the struggle of this teacher in balancing her tasks.

\section{Extract 5}

I have to struggle to handle the house chores and kids, somehow I realized that my chore business as a teacher needed to be given a priority.

(P4/FC/OEI)

The findings indicate that family responsibility, the need for double tasking and leading a hectic life are the challenges of the student-teachers on family commitments. Since the participants of this study are adult learners, all of them had a family to look after. Hence the responsibility of filial piety could not be avoided. In some of the cases, sharing the problems with colleagues who were in the same predicament turned out to be helpful in putting through their studies. Another helpful aspect is having a supportive spouse, where it had been described as a great support in producing less stressful situation among the teachers in facing the pressure as a student-teacher.

\subsection{Time management}

Time management is significantly positively related to academic achievement of students, according to the behaviorists of time management (Razali, Rusiman, Gan, \& Arbin, 2018). Hence time planning is the most significant correlated predictor. This study consistently found that time management is a challenge to the student-teachers. The participants had a significantly fair share of time constraints in managing their life as adult learners. That was expressed by (P2, OEI) in extract 6 .

\section{Extract 6}

I had to finish off my lesson plan for teaching. (pause) at the same time there was my assignment waiting to be completed. On some nights, I had a very late sleep to complete both. That was stressful, not having enough rest.

(P2/JC/OEI)

Apparently applying for leave has become a solution for (P1, OEl. That was expressed in extract 7. 


\section{Extract 7}

I would have to apply for leave to meet the deadline for my assignment, as I couldn't be able to cope with the juggling of tasks between studies and school work.

(P1/JC/OEI)

There is a need to have a clear understanding of students' time management for this sample of student-teachers. First of all, the personality variable under investigation to achievement striving was limited. Other variables such as optimism, stress and self-efficacy are likely to influence the solution to managing the time.

Time management is crucial to adult learners to ensure some kind of order in their life. This research found that the participants face time constraints in their learning as they are teaching full time in school apart from managing a family and studying a part-time. Work-study-life balance is one solution to organise not only their time, but also their life in general.

\subsection{Mental health issue}

According to the interviews conducted in the BeLL-project, there is a significant strong connection between the social aspect of studying and mental well-being.

The chaotic lifestyle has caused this group of teachers to be facing health and mental issue. Without having enough sleep and the requirement to meet the deadlines of tasks on the roller-coaster time had caused them to be suffering from depression and stressful situation.

Despite the perceived difficulties in handling double-tasking between studies and her career, (P4/OEI) still managed to do outside job for her own personal reason. The extra burden, had almost cost her studies, where she needed to repeat another semester to be graduated. That was expressed in extract 8 .

\section{Extract 8}

During that time of studies, I was also involved in part-time job. As a tuition teacher of four different centers, it had been really tiring and I had a hard time in focusing on my studies. In fact, I had to extend for another semester before I finally managed to be graduated.

(P4/OEI) 
(P5/OEI) started to realize that at one point of her student-teacher days, she needed to be strong in order to complete her studies despite all the challenges in her relationship with her spouse. Extract 9 represents her situation.

\section{Extract 9}

I was depressed and feeling like giving up on my studies at times. On top of that, my husband was cheating me behind of that my back, that was the last straw.

(P5/OEI)

Learning can be associated with stress and anxiety, and erode factors that have helped people maintain good mental health. Hence, there should be ways and solutions for teachers with mental health. Online learning solutions provide much-needed effectiveness for teachers, allowing them to maximize the potential for individual learning curves. Many online learning solutions account for self-paced learning and allow teachers to work to meet scheduled targets. Other potential benefits of online professional development are flexibility and versatility and improvement of teacher retention by enabling teachers to become more directly involved in their own learning and professional growth. Hence, face to face cooperated with online learning is recommended to adult learners as they would have their own time and space for learning process in doing a First-degree on a part-time basis.

\section{Conclusion}

Previous study done by Silva et al. (1998) found that four specific factors can serve as barriers to further education for adult learners, namely lack of time, family commitments, distance as well as financial expenses. Interestingly, financial and distance did not seem to be much a challenge to the ELS teachers in this research who had followed the program due to the reason that it is highly subsidized by the Ministry of Education, and the location of the living places of the participants were located generally within the same district of the campus they were studying in. The findings of this research lay the foundation of insights to the people who are involved in the process of planning and implementing teachers' professional development programs of the ideas and consideration in understanding language teachers' selves and needs while pursuing their first degree. It will also be of beneficiary and insights to the in-service teachers who are intended to further their studies on part time basis, on the challenges while 
following the program. In one way or another, it can prepare the teachers on unforeseen challenges that are to be faced by them if they are to follow the program.

\section{References}

[1] Ali, M. S. (2002). Professional development of ESL teachers in primary schools. Jurnal Pendidikan IPBA, 2(5), 43-59.

[2] Badri, M., Al Nuaimi, A., Guang, Y., \& Al Rashedi, A. (2017). School performance, social networking effects, and learning of school children: Evidence of reciprocal relationships in Abu Dhabi. Telematics and Informatics, 34(8), 1433-1444.

[3] Choy, S. (2002). Nontraditional undergraduates. Washington, DC: Center for Education Statistic.

[4] Darling-Hammond, L. \& McLaughlin, M.W. (1995). Policies that support professional development in an era of reform. Phi Delta Kappan, 76(8), 597-604.

[5] Gorard, S., Adnett, N., May, H., Slack, K., Smith, E., \& Thomas, L. (2006). Review of widening participation research: Addressing the barriers to participation in higher education. Bristol: HEFCE.

[6] Jamil, H., Abd Razak, N., Raju, R., \& Mohamed, A. R. (2010). Teacher professional development in Malaysia: Issues and challenges. Africa-Asia University Dialogue for Educational Development Network, 1(1), 85-102.

[7] Jones, L. B. \& Rothbart, M. K. (2003). Development of executive attention in preschool children. Developmental Science, 6(5), 498-504.

[8] Kazis, R., Callahan, A., Davidson, C, Mcleod, A., Bosworth, B., Choitz, V., \& Hoops, J. (2007). Adult learners in higher education: Barriers to success and strategies to improve results. Washington, DC: U.S. Department of Labor, Employment and Training Administration.

[9] Mathews-Aydinli, J. \& Taylor, K. (2005). Online professional development for adult ESL educators. Washington, DC: Center for Applied Linguistics.

[10] Ministry of Education, Malaysia. (2013). Malaysia education blueprint 2013 - 2025. Putrajaya: Kementerian Pendidikan Malaysia.

[11] Nias, J. (1996). Thinking about feeling: The emotions in teaching. Cambridge Journal of Education, 26(1), 5-16.

[12] Riessman, C. K. (1993). Qualitative research methods, Vol. 30. Narrative analysis. Thousand Oaks, CA, US: Sage Publications, Inc. 
[13] Razali, S. N. A. M., Rusiman, M. S., Gan, W. S., \& Arbin, N. (2018). The impact of time management on students' academic achievement. Journal of Physics Conference, 995(1), 1-7.

[14] Silva, T., Calahan, M., \& Lacireno-Paquet, N. (1998). Adult education participation: Decisions and barriers. Review of Conceptual Frameworks and Empirical Studies. Washington, DC: U.S. Department of Education.

[15] Teacher Education Division, Malaysia. (2014). Pelan induk pembangunan profesionalisme keguruan. Putrajaya: Kementerian Pendidikan Malaysia.

[16] Wragg, T. (2002). Interviewing. In Coleman, M. and Briggs, A (2002), Research methods in educational leadership and management. London: Sage Publication. 